1989

\title{
Is Tragedy Possible?: A Comment on George Fletcher's "The Right and the Reasonable"
}

Kenneth S. Gallant

University of Arkansas at Little Rock William H. Bowen School of Law, ksgallant@ualr.edu

Follow this and additional works at: http://lawrepository.ualr.edu/faculty_scholarship

Part of the Law and Philosophy Commons

\section{Recommended Citation}

Kenneth S. Gallant, Is Tragedy Possible?: A Comment on George Fletcher's "The Right and the Reasonable" 37 Am. J. Comp. Law 595 (1989).

This Comment is brought to you for free and open access by Bowen Law Repository: Scholarship \& Archives. It has been accepted for inclusion in Faculty Scholarship by an authorized administrator of Bowen Law Repository: Scholarship \& Archives. For more information, please contact mmserfass@ualr.edu. 


\title{
Comments
}

\section{IS TRAGEDY POSSIBLE?: A COMMENT ON GEORGE FLETCHER'S "THE RIGHT AND THE REASONABLE"}

\author{
Kenneth S. Gallant*
}

Is there a possibility of a tragic conflict of legal rights? Professor George Fletcher, in "The Right and the Reasonable"1 rejects such a possibility. He searches instead for a single Right every time a conflict arises. Such a Right may be qualified, or even overcome, in any given situation; but Fletcher maintains that in any given conflict, only one party may be in the Right. ${ }^{2}$ He calls this conception, with its basis in the civil law, "monistic." Its associated methods of legal reasoning he calls "structured" because they require that determinations be made in a certain order: They require a court first to determine which party has the Right, then to decide whether the Right is limited or overridden in the particular case.

Fletcher contrasts this view with the "pluralistic" view he attributes to the common law, which allows for conflicting fundamental rights. The common law uses legal reasoning that he terms "flat" because conflicts between principles are mediated by a vague, one-step test of reasonableness, not by a structured method imposed by the legal system. "Flatness" is the lack of an ordering structure in analyzing facts: One looks at one time to whatever part of the factual situation will dispose of the case and to the criteria that will be applied to those facts to mediate between principles. ${ }^{3}$ Perhaps, therefore, a more appropriate characterization of the civil law system for analysis of conflicts would be "ordered," while that of the common law system would be "random access."

* Associate Professor and Director of Clinical Programs, University of Idaho College of Law.

1. Fletcher, "The Right and the Reasonable," 98 Harv. L. Rev. 949 (1985).

2. Id. at 978, 980. Much of "The Right and the Reasonable" is provisional, setting forth a program for future investigation. See id. at 982. At the core of his masterpiece, Rethinking Criminal Law Fletcher restates the problematic nature of his inquiry:

[T] here is no straightforward argument to prove that the substantive issues bearing on wrongdoing and culpability are subject to principled analysis.

This entire book seeks to come to grips with that problem.

Fletcher, Rethinking Criminal Law 549 (1978) [hereinafter Rethinking Criminal Law]. Although critical of some of Fletcher's conclusions, this paper is offered in the same spirit of inquiry.

3. Fletcher, supra n.1, at $951,962-64$. 
His paradigm for showing the distinction between these two methods of reasoning is taken from the criminal law: the issue of putative self-defense, where $A$ attacks $B$ in the reasonable but mistaken belief that $\mathrm{B}$ is attacking him. ${ }^{4}$ According to the monistic approach, A's action cannot be justified, that is, "in harmony with the Right." Instead, the monists would argue, A's actions may only be "excused" as a product of mistaken but honest belief; and therefore A may be spared punishment. 5

The first point of this account, that $A$ is not right, is, I think, wrong. ${ }^{6}$ Quite properly, Fletcher argues that legal rules ought to enable any actor, insofar as possible, to determine whether a contemplated action is within the law. ${ }^{7}$ If that is so, what account of criminal law could fail to exonerate both A and B? ${ }^{8}$ And not merely exonerate them, but do so for the same reason? A and B act upon similar perceptions, and they act indistinguishably; that is, either would act the same way in the other's shoes. In a system in which blameworthiness rather than impurity ${ }^{9}$ or regulatory efficiency ${ }^{10}$ is the criterion of guilt, the burden upon those who would deny the equivalence of the positions is great. Fletcher himself has argued to retain blameworthiness as one of the core elements of criminal liability. ${ }^{11}$

The argument to treat A and B similarly does not confuse ques-

4. Id. at $971-80$.

5. Id. at 971-73. Fletcher cites as antagonistic to this view Charles Fried, Right and Wrong 48 (1978). Fletcher, supra n.1 at 974 n.109.

6. See Fried, supra n.5 at 48.

7. Fletcher, supra n.1 at 976.

8. The common law has not, however, carried this reasoning to its limits. For example, an act of deadly violence performed in the sincere but unreasonably mistaken belief it is necessary in self-defense only reduces a deliberate killing from murder to manslaughter. Cf. Fletcher, supra n.1 at 975. But this is fairly easy to explain: The failure of the defendant to determine what was reasonable is a legally cognizable failure. Harder to explain is the confusion concerning the criminal liability of the third party "defender" who reasonably but wrongly concludes that another is in danger. See Sanford Kadish, Stephen Schulhofer, \& Monrad Paulsen, Criminal Law and Its Processes 732-33 (4th ed. 1983).

9. Fletcher has elsewhere provided a highly suggestive account of the "taint" associated with people and objects that were involved in deaths of others in early English Law. Rethinking Criminal Law, supra n. 2, at 343-49 (1978).

A pair of examples to illustrate the difference between impurity or taint and fault may be useful here. Oedipus' killing of his father and marrying of his mother are faultless because unknowing on his part. Nonetheless, he is tainted and impure because of these acts. On the other hand, Orestes' killing of his mother in revenge for the murder of his father presents the question of the blameworthiness of the act. Aeschylus, The Eumenides.

10. The trend towards "strict liability" crimes in the area of public safety and health regulation presents an example of this sort of crime. See Rethinking Criminal Law, supra n. 2 at 716-17.

11. The word he uses is "accountability." Id. at 729-30. This is not to say that strict liability is not useful at some of the edges of criminal law, or that even Fletcher would find it that way. He does, however, believe it to be a "dangerous instrumentality that should be handled with the utmost care." Id. at 722. 
tions of law and morality, as Professor Fletcher suggests. ${ }^{12} \mathrm{He}$ distinguishes the rule of law from that of morality by defining law (the Right) as "an objective framework for regulating practical affairs in civil society"13 (a reasonable minimum requirement for an ideal set of laws). However, just because law and morality overlap does not mean that the two are confused. More importantly, the rule of law that one may attack another when the facts are such that a reasonable person would believe he or she was under attack by the other meet Professor Fletcher's criterion of being an objective rule for regulating practical affairs. ${ }^{14}$

The best reasonable intentions possible in the circumstances is a sensible demand for the criminal law to make. It is also sensible not to distinguish between two people with identical intentions who come into conflict. Fletcher's view of the Right requires omniscience of each party as to facts relevant to any transaction. Such omniscience simply does not exist concerning most transactions. The common law's recognition that two reasonable actors may through faultless error come into irreconcilable conflict is an affirmation of human limitations and is therefore not vulnerable to a charge of being subordinate to individual moralities.

In other words, any system of laws sets as its task the regulation of individuals in concrete situations. ${ }^{15}$ It is not a criticism that the law seeks to direct individuals' conduct in the light of what those individuals believe is the state of the world-at least with the additional caveat that they must have made appropriate efforts to ascertain the circumstances in which they are acting. ${ }^{16}$

The tragedy of an imperfect self-defense arises from lack of knowledge. The omniscient observer ${ }^{17}$ sees the conflict as pathetic rather than tragic, because pity inheres in the conflict-generating error. Thus, in a literary sense, the tragedy of imperfect self-defense and similar conflicts is not the deadly conflict, but the human condition which binds us to act on insufficient information. Othello would seem evil but for the fact that humans must act on present knowledge with unforeseeable consequences. This bond with the ordinary human condition is what ennobles him.

Fletcher's putative self-defense example is not an argument against pluralism, but against the tragic human condition which binds us to act on insufficient information. This leads to the question of whether tragic conflicts of rights could arise if there were perfect information. Generation of a tragic conflict in a state of perfect information would require a case in which neither side could

12. Fletcher, supra n. 1 at $974-75$.

13. Id. at 974, following Immanuel Kant.

14. Common law practice requires the additional, "subjective" element that the putative defender must actually believe he or she is being attacked.

15. See Fletcher, supra n. 1 at 974.

16. For the moment "appropriate" is left undefined.

17. To obtain the monistic law based on objective Right, Fletcher must at least argue that courts should aim to fill this role as closely as may be. 
prevail without generating "a sense of loss" of a fundamental value. ${ }^{18}$ Both parties to a dispute would claim fundamental rights, at least one of which must be sacrificed in any resolution of the dispute. If no such example of conflicting rights could be found, then "monism" might well be a goal towards which the legal system ought to strive.

It is central to Fletcher's conception of law that fundamental values may possibly be found that do not depend upon the particular cultural context in which they occur. ${ }^{19}$ I do not wish at present to abandon such a possibility; but in the discussion of tragic conflict which follows, the element of cultural dependence is strong: One feels that the conflict arises out of values unique to the culture in which it occurs. Yet the tragedy is felt across cultures, suggesting that there may be a non-relativist ethic that allows tragic conflicts of fundamental, irreconcilable rights.

Socrates' death provides the exemplary case of tragic conflict in the law. Socrates was condemned to die for the teaching and corruption of Athenian youth. In the Crito, Plato shows him refusing an opportunity to escape to safety although he admitted that his condemnation was wrong. The sense of loss, both to Socrates and to the community, of his freedom to teach is immeasurable. ${ }^{20}$ Yet in the Crito, Socrates built the remarkable case that his loss cannot be avoided, and another loss would follow from rebellion: loss of the necessary, fundamental, and usually just authority of the state. At the time of the Crito, there was no resolution to Socrates' dilemma that did not forfeit one of these values.21 So long as we believe his argument as to the fundamentality of obedience to a basically justif imperfect or imperfectly administered-law, his dilemma is tragic. His good cheer in the face of death does not detract from the fact that his sentence was a loss to the fundamental role of free inquiry.

18. Cf. Guido Calabresi and Philip Bobbitt, Tragic Choices 17 (1978) (suggesting that choices of allocation of scarce resources are tragic only when they are seen by the society as involving conflicts of underlying values, and thereby building a framework in which tragedy is relative to specific cultures).

19. Fletcher, supra n.1 at 982.

20. I see Socrates' loss of his freedom, rather than his life, as his principal loss because that is the way he purported to see it. Plato, Apology 29 c,d,e.

21. If, at an earlier time, the tragic dilemma could have been avoided by the acquittal of Socrates, the trial of this case did not necessarily present a tragic choice. If the Athenian jury should under the law have acquitted Socrates, no tragic problem was presented at that point, for acquittal would have required loss of no basic value: the conviction was just a mistake. One might therefore suggest that the example is like the putative self-defense example in that the tragic conflict arises out of the mistaken conviction.

The ground is subtlely different if the jury could, but need not, have acquitted Socrates under the law; and was allowed to weigh basic values in reaching its decision. Under Calabresi and Bobbitt's formulation, the conflict may be seen as tragic if the Athenians would have seen it so. See supra note 18. But I suspect Fletcher would say there is no tragedy here, for Socrates should have been acquitted.

The third possibility, that the law required conviction, implies, so long as we believe Socrates' argument, that the tragedy inhered in the situation from the beginning. 
The fact of this tragedy does not preordain Socrates' choice of death; but his decision shows us the fundamental nature of the rights represented by each side, and the tragedy of the requirement that Socrates choose. The choice of death highlights the importance of obedience to the law of the state, but does not denigrate the right the teacher sacrificed. Because no one truly wanted Socrates to die, only by death could Socrates demonstrate that both values in conflict were fundamental.

A "monist" view of the law denies Socrates his tragedy. The Right is either on the side of the state or not. If not (we would say without Socrates' teaching), the Socrates of the Crito is either a fool or a suicide, but he is certainly not admirable. If the Right is with the state, then Socrates' life of freethinking has been blameworthy. ${ }^{22}$ Only if both Socrates and the state have irrebuttable claims of right, which Socrates contends is the case, can both his life and his death be justified. ${ }^{23}$

Pluralism does not reject the possibility of an objective science of law or morals. In this sense it is not the opposite of monism, which assumes that such a science is possible. Rather, a legal system may be pluralistic if it believes either that there is a moral relativism by which answers to concrete legal problems ought to change depending on cultural differences or that an objective science of law or morals can exist, but may be incomplete. That is, a pluralist conception of law can provide a method to determine many possible controversies, but may show that there are some undecidable cases of fundamental conflict. ${ }^{24}$

It is the common law's ability to recognize conflicting rights, rather than a unitary Right, which gives it strength. Using the common law method of reasonableness, one can admit that both sides of a dispute are in some sense right, but that a legal adjudication by its nature must either declare one party the winner or somehow split the difference.

Moreover, there is a serious problem with the notion of "structure" as Fletcher presents it in his model of "structured legal reasoning." It allows values other than those defining the Right to prevail. Once a so-called Right in one party is defined, Fletcher's method requires an examination of the Right to determine if it has been "abused" in a given case. If so, the party abusing the Right is

22. The difference between doing wrong and being accountable, upon which Fletcher insists, will not work here, because Socrates goes out of the way to make himself accountable for his acts.

23. One can read Sophocles' Antigone as the same story. If one does, however, Sophocles' heroine is no moral match for Plato's Socrates, nor is Creon the villain of tradition. The tragedy is apparent only to the poet and audience-not to Antigone, and not, until the end, to Creon.

24. This echoes the use of the word "undecidable" in mathematical logic to describe propositions which, in a given system, cannot be proven or disproven. I doubt this analogy should be pushed too far. 
stripped of protection. ${ }^{25}$ For example, a person generally has the right to protect her property. If that person uses deadly force to prevent a minor theft, however, she has abused that right. Professor Fletcher claims that the notion of abuse thus limits the "fundamental right" of self protection.

In what sense is "fundamental" being used here? It seems to mean "general" rather than, as necessary to Professor Fletcher's argument, "most important." The right of self-protection surely is one of the most general rules we use in defining conduct, but one cannot say it is fundamental in the sense of being the most important in this case. As Fletcher admits, respect for life, even the life of a wrongdoer, is at least as important. ${ }^{26}$ In the structure of "structured" legal argument, however, in this situation, respect for life is not the fundamental value. Rather, it is used to limit the applicability of the Right, and one cannot discern the principled basis, other than a rule of reasonableness, on which this limitation is done. For his argument work, Fletcher needs to define fundamental rights, not merely general ones, from which reasoning may begin; for as he declared, "[a]n absolute right occupies the available moral space." 27 The method of discovering and upholding the Right is morally superior to resolving conflicts by reasonableness only if the Right is not in the end subjected to a test of reasonableness. His example unfortunately shows that this is not the case. The Right is as subject to limitation as the substantive principles of the common law.

All of this is not to say that the common law method of using reasonableness to mediate conflicts of rights in practice provides the most satisfactory resolution of all hard cases. Although the common law system may have the virtue of admitting the existence of rights that conflict, reasonableness does tend to dull the sharp edges of the conflict. A good example of this tendency in the common law system comes from the adjudication of the right of black students to attend private schools attempting to remain racially segregated. In Runyon v. McCrary, ${ }^{28}$ the Supreme Court upheld such a right in the face of claims that it violated the defendants' rights of free association, the parents' right to educate their children as they saw fit, and both the parents' and defendants' right to privacy. In rebutting these claims, the Court subordinated the issue of the fundamentality of these rights to that of whether the statute forbidding such discrimination was a "reasonable government regulation." 29 The Court did not admit that the loss of the right to choose the way of life of one's child, even to choose evilly, could have been a very important loss. In this sense, Fletcher's use of the term "flat" to describe common law legal reasoning is highly suggestive. While it does not re-

25. Fletcher, supra n. 1 at 968.

26. Id. at 968-69.

27. Id. at 978.

28. 427 U.S. 160 (1976). Despite his criticism of the opinion in this case, the author believes it was correctly decided.

29. Id. at 178. 
quire the choice of a single value as fundamental, it tends, if incautiously used, to make none look so.

The common law rule of reasonableness provides a rule for mediating, or at least avoiding, some tragic conflicts, but does not do so for all such conflicts. The common law will respond to the putative self-defense case by acquitting the putative self-defender and his victim who responds in actual self-defense, thus affirming the position taken by each in the situation presented to each. This, however, is the easy case because the two participants in the fight are not adversaries in the court cases.

The structural principles of the common law cannot alone resolve the tragic conflicts of the Crito or of Runyon v. McCrary; this is equivalent to saying the science of law may be incomplete. Indeed, without sufficient thought, these principles may well suggest a flat, unsatisfactory resolution of the conflicts. However, the failure of structure to provide a means for decision is not a fatal flaw in the common law, but a concealed strength. It allows judges and the public to see that irreconcilable moral conflicts are in fact irreconcilable by reasoning alone. Such a recognition prompted Socrates to choose state-administered death. At the end of his moral conflict, the first rationalist accepted the limits of rational and systemic thought as applied to moral problems. Confrontation of these issues by the less heroic (i.e., almost everyone else) may tend to produce flight from their fundamentality, that is, to produce flatness.

This is naturally uncomfortable to those required to run a system of justice, who are required to decide controversies. Nonetheless, exposure of how fundamental rights differ is morally superior to the papering over of the tragic choice by a preliminary requirement of choosing on the basis of a foreordained "Right."

The long association of common and civil law methods with different Western cultures suggest examples of how these theoretical arguments may have affected the development of those cultures. This discussion has suggested that the common law method, with its ability to consider different claims of right on an equal footing, allows the recognition of difficult moral choices. By doing so, it tends to tolerate a variety of viewpoints. While not inherently relativist, this sort of scheme at least allows suspension of ultimate judgment as to which rights are more fundamental than others until some sort of consensus can be reached. Thus, while unsatisfactory as a final exegesis of the conflict between equality and free association, the opinion in Runyon v. McCrary is part of a necessary dialogue and allows the dialogue to continue.

On the other hand, there are some facts in the history of those cultures that have adopted "structured" legal reasoning as an elaboration of the Right which should give Fletcher pause. The Right can all too easily be perverted in the popular mind from a principle of justice, which requires deep thought to be applied properly, to a set of political rules to be applied rigidly. In the guise of Right then, a 
system might become totalitarian or evil. The possibility of this perversion grows insofar as the popular perception of the legal system is that "Right need never yield to Wrong." 30 That is, if the popular view of a Right is strong enough to reject limitations on the Right, the Right is easier to pervert. There were many factors which gave rise to German National Socialism, but could it be that the monistic view of the Right facilitated it? That is, once a political program is accepted because it promises fundamental changes, that program, in the eyes of demagogic supporters, may no longer be subject to limitation. Its demonic tendencies are then wholly freed. To the extent that Fletcher relies on German and Russian examples as showing the virtues of the Right, ${ }^{31}$ he must also attempt to account for the effect of this way of thinking upon indigenous totalitarian movements.

In a culture recognizing the possibility of conflicts of fundamental interests, at least a significant minority in that culture can press the evil tendencies out. Thus, it may be that this characteristic of the common law helped make possible legal remedies for American race discrimination within the prevailing political structure.

"The Right and the Reasonable" concludes with the question of whether argument should legitimate culture or vice-versa.32 However, this question is more complicated than Fletcher suggests. Of course argument may be used to legitimate-or delegitimate-some aspects of culture, including legal culture. But law exists only in a larger culture, and it is possible that the arguments that legitimate legal culture cannot be made without reference to and structuring by the larger culture. Socrates taught that the existence of a working culture is itself a value that argument may not ignore.

Of course the "monists" have a final reply: Life may indeed present a tragic vision, but the law is not the whole of life. The failure of any system of positive law to work without transcending concepts such as Right or reason suggests that even the best possible system would leave tragic dilemmas, and thus present to us the true outline of the tragic. The answer of the pluralists may now be merely preliminary. The openness of a pluralist system to tragedy at least appears to promote reason in politics by exposing conflicting values and forcing a dialogue about those values. If this is true, that openness alone would justify the common law method.

30. Fletcher, supra n. 1 at 968 . This of course cuts loose from the proper operation of the system of the Right as Fletcher describes it and as the conscientious Continental lawyer practices it: i.e., the Right must yield to other values in certain circumstances.

31. Fletcher, supra n.1 at 964-71, 978 (German law); id. at 964-65 (Soviet law). While none of Fletcher's examples of German legal reasoning comes from the Nazi era, he implies that they reflect German thought over a long period of time by using examples from Kant's time to the present day. See, e.g., id. at 967-68.

32. Id. at 982 . 